\title{
Motor Activity and Physical Abilities of Students in the Conditions of Restrictions of COVID-19
}

\author{
Oleksandr Mozolev ${ }^{1, *}$, Oleksandr Polishchuk ${ }^{2}$, Inna Shorobura ${ }^{3}$, Valentina Miroshnichenko ${ }^{4}$, \\ Klavdiia Tushko ${ }^{4}$, Volodymyr Voloshyn ${ }^{5}$, Ihor Tomkiv ${ }^{6}$, Oleksandr Binkovskyi ${ }^{6}$
}

\author{
${ }^{1}$ Department of Theory and Methodology of Physical Culture and Valeology of Khmelnytskyi Humanitarian-Pedagogical Academy, \\ Ukraine \\ ${ }^{2}$ Department of Social Disciplines, Khmelnytskyi Humanitarian-Pedagogical Academy, Ukraine \\ ${ }^{3}$ Department of Pedagogy, Khmelnytskyi Humanitarian-Pedagogical Academy, Khmelnytskyi, Ukraine \\ ${ }^{4}$ Department of Psychology, Pedagogy and Socio-Economic Disciplines of the Bohdan Khmelnytsky National Academy of the State \\ Border Guard Service of Ukraine, Khmelnytsky, Ukraine \\ ${ }^{5}$ Department of Physical Training and Personal Safety, Pedagogy of the Bohdan Khmelnytsky National Academy of the State Border \\ Guard Service of Ukraine, Khmelnytsky, Ukraine \\ ${ }^{6}$ Department of Managerial Personnel Training of the Bohdan Khmelnytskyi National Academy of the State Border Guard Service of \\ Ukraine, Khmelnytskyi, Ukraine
}

Received January 27, 2021; Revised March 16, 2021; Accepted April 18, 2021

\section{Cite This Paper in the following Citation Styles}

(a): [1] Oleksandr Mozolev, Oleksandr Polishchuk, Inna Shorobura, Valentina Miroshnichenko, Klavdiia Tushko, Volodymyr Voloshyn, Ihor Tomkiv, Oleksandr Binkovskyi, "Motor Activity and Physical Abilities of Students in the Conditions of Restrictions of COVID-19," International Journal of Human Movement and Sports Sciences, Vol. 9, No. 3, pp. 428 - 435, 2021. DOI: 10.13189/saj.2021.090306.

(b): Oleksandr Mozolev, Oleksandr Polishchuk, Inna Shorobura, Valentina Miroshnichenko, Klavdiia Tushko, Volodymyr Voloshyn, Ihor Tomkiv, Oleksandr Binkovskyi (2021). Motor Activity and Physical Abilities of Students in the Conditions of Restrictions of COVID-19. International Journal of Human Movement and Sports Sciences, 9(3), 428 - 435. DOI: $10.13189 /$ saj.2021.090306.

Copyright $\mathrm{C} 2021$ by authors, all rights reserved. Authors agree that this article remains permanently open access under the terms of the Creative Commons Attribution License 4.0 International License

\begin{abstract}
The article analyzes the results of the research of impact of limitations of motor activity of students in the conditions of pandemic COVID-19 on the indicators of functional and physical condition of students 17-19 years who studied on the $2^{\text {nd }}$ course in Khmelnytskyi Humanitarian-Pedagogical Academy. The study involved 121 students ( 89 girls; 32 boys). Methods: The assessment of the state of the cardiovascular system: heart rate at rest (HR); systolic blood pressure (SBP); diastolic blood pressure (DBP) has been done; assessment of the respiratory system (RS) has been conducted. The analysis of morphofunctional changes in the following indicators has been done: life index (LI), body mass index (BMI), Index of Robinson (IR), Ruffier-Dixon Index (RDI). Results: It is established that the restriction of motor activity has led to functional changes in the bodies of students, reducing their efficiency and recovery of the organism after physical exercises. In both groups of students after four months of research, there was deterioration in performance (RS), (LI); (IR); (RDI);
\end{abstract}

(BMI). After nine months of quarantine restrictions, there was a gradual improvement in functional parameters in both groups, indicating the adaptation of students to the new conditions of limited motor activity. At the same time, the functional indicators failed to reach the initial level. It is found that during the first four months there was a decrease in physical fitness of students, namely: the development of strength by $34 \%$ in girls $(\mathrm{p}<0,001)$ and $28 \%$ in boys $(p<0,001)$; coordination abilities by $12 \%$ in girls $(p<0,01)$ and by $13 \%$ in boys $(p<0,01)$; development of speed and strength abilities by $15 \%$ in girls $(\mathrm{p}<0,01)$ and by $13 \%$ in boys $(p<0,01) ; 5 \%$ speed development in girls $(p<0,05)$ and $4 \%$ in boys $(p<0,05)$. At the second phase of the research, some students ( $12 \%$ - girls and $21 \%$ - boys) were able to reach the previous physical condition. These are mainly the students who led an active lifestyle before the pandemic and sought additional exercise during quarantine restrictions. Conclusions: the processes of adaptation and restoration of motor activity under quarantine restrictions of boys were faster. After nine months, in the majority of 
exercises tested, the boys' level of physical fitness reached $95-98 \%(p<0,001)$ of the initial level; in girls it was 91-94\% $(\mathrm{p}<0,001)$. Only the performance of exercises for the development of strength in boys corresponded to $88.6 \%$ of the initial, and in girls to $81.2 \%$.

Keywords Motor Activity, Physical Fitness, Students, Functional Abilities, COVID-19

\section{Introduction}

Motor and physical activity is an extremely important, fundamental factor in the formation, maintenance, promotion of human health and development, especially in childhood and growing age. Due to the body's ability to self-regulate its adaptation to changes in the external environment takes place, the body becomes more stable and viable. When doing physical exercises physiological mechanisms in the human body trigger that enhance the functions of not only muscles but also the respiratory, cardiovascular, nervous and digestive systems. Everyday physical activity is an integral part of a healthy lifestyle of student youth, the basis of harmonious development of their body and well-being [1-2]. Physical activity can improve not only physical health, but also mental health and general well-being. The optimal level of physical activity should meet the natural need of a person to move in order to strengthen their health, promote efficiency, as well as positively affect the intellectual component of life [3].

Motor activity plays the role of regulator of development of the organism, it is a necessary condition for the formation and improvement of a person as a biological being. Physical activity is determined by the sum of movements performed by a person in the process of vital activity. When measuring motor activity, scientists use various criteria and techniques that allow to obtain sufficiently objective information and do not require complex equipment [4].

New requirements in the organization of daily life and student education, caused by the spread of the COVID-19 pandemic in the world, have led to various restrictions in the organization of education, physical culture, sports, and leading an active lifestyle. Anti-epidemic measures introduced in the state have a negative impact on the health and mental state of students due to the sharp decline in physical activity and access to sports facilities [5]. Due to the requirement to stay at home for a long time, students lose the necessary amount of physical activity to which they are accustomed, and gradually enter the risk category of students who lead a sedentary lifestyle. The result of this is natural deterioration in health, well-being and reduced efficiency [6-7].

Physical fitness depends on the amount of motor activity. The individual norm of motor activity is determined by the achievement of a specific physical condition, which can be expressed by quantitative indicators of physical performance, physical fitness, and the functional state of the main body systems [8-9]. Therefore, in order to study the motor activity of students during the pandemic COVID-19, we measured physical and morphofunctional indicators and conducted comparative analysis of their changes with the indicators of the previous year of study.

The purpose is to analyze the physical development and functional abilities of students in the conditions of COVID-19 restrictions.

The objectives:

- to study the indicators of physical development of students aged 17-19 in the period 2019-2020;

- to determine the level of development of physical and morphofunctional indicators of students before the COVID-19 pandemic and after four and nine months of motor activity limitations;

- to investigate the influence of COVID-19 on the morphofunctional indicators and the level of physical development of students.

\section{Materials and Methods}

The participants of the experiment: 89 female students and 32 male students aged 17-19, who were studying in the $2^{\text {nd }}$ course on Khmelnytskyi Humanitarian-Pedagogical Academy.

Methods. To obtain the necessary information, we used general scientific methods of the theoretical level of research, namely: analysis of scientific and methodological sources; questioning; pedagogical observation; measurement of physical, functional and morphological indicators; diagnosis, testing, comparative analysis; and methods of mathematical statistics.

Organization of the research: The research work was conducted on the basis of Khmelnytskyi Humanitarian-Pedagogical Academy in the period from March 2020 to December 2020. Researched: 121 students (89 girls and 32 boys) aged 17-19.

Stages of the research:

- March 2020 - the initial stage of the research (determination of baseline indicators);

- June 2020 - the first stage of the research (determination of functional indicators and indicators of physical development after strict restrictions of COVID-19);

- December 2020 - the second stage of the research (determination of functional indicators and indicators of physical development after the lockdown during the period of adaptive quarantine).

The study included the following phases:

1. survey of students on the state of health, well-being, opportunities for doing physical exercises and sports;

2. conducting a medical examination and determining the functional indicators of the physical condition of students: heart rate at rest (HR); systolic blood 
pressure (SBP); diastolic blood pressure (DBP); vital capacity of the lungs (VC);

3. determining the level of development of morphofunctional capabilities and health status of students, which included obtaining results in the following indicators:

a) life index (LI) - characterizes the functional abilities of the respiratory system;

b) body mass index (BMI) - characterizes the assessment of the correspondence of body weight to human height;

c) Index of Robinson (IR) - quantitative assessment of human energy potential;

d) Ruffier-Dickson's Index (RDI) - characterizes the physical performance of the heart;

e) Recovery time after 20 squats (sec) characterizes the recovery of the body after physical exercises.

4. testing of the level of physical fitness:

1) bending and extension of the arms based on the bench $(30 \mathrm{~cm})$ in horizontal position - for girls; pull-ups on a chinning bar - for boys (strength);

2) standing long-jump (explosive strength);
3) holding balance on one leg (long fly vault) (coordination abilities, static balance);

4) Burpie's test (determines the development of the ability to general coordination of body movements combined with the differentiation of speed-strength parameters);

5) shuttle run of $4 \times 9 \mathrm{~m}$ (agility).

5. conducting a comparative analysis of the impact of COVID-19 restrictions on morphofunctional parameters and the level of physical development of students after four and nine months of motor activity restrictions.

\section{Results}

To solve the objectives and achieve the goal of the research, we measured morphofunctional indicators that reflect the work of functional systems of students. We conducted the comparative analysis of the established indicators in accordance with gender features and age development of students at each phase of the research. The results are presented in table 1 .

Table 1. Dynamics of indicators of morphofunctional abilities of students at different phases of the experiment $(\mathrm{X} \pm \mathrm{m})$

\begin{tabular}{|c|c|c|c|c|c|c|}
\hline \multirow[b]{2}{*}{ Indicators } & \multicolumn{6}{|c|}{ Research phases } \\
\hline & $\begin{array}{l}\text { At the beginning } \\
\text { of the experiment }\end{array}$ & $\begin{array}{c}\text { At the end of } \\
\text { phase } 1\end{array}$ & Changes & $\begin{array}{c}\text { At the end of } \\
\text { phase } 2\end{array}$ & Changes & $\begin{array}{l}\text { General } \\
\text { changes }\end{array}$ \\
\hline \multicolumn{7}{|c|}{ Group of girls $(n=89)$} \\
\hline Height $(\mathrm{cm})$ & $164.2 \pm 10.5$ & $164.2 \pm 10.5$ & - & $164.2 \pm 10.5$ & - & - \\
\hline Weight (kg) & $57.4 \pm 7.6$ & $59.8 \pm 8.2$ & $+2.4 \pm 0.6$ & $59.0 \pm 6.7$ & $-0.8 \pm 1.5$ & $+1.6 \pm 0.9$ \\
\hline $\mathrm{BK}(\mathrm{ml})$ & $2780 \pm 70$ & $2650 \pm 90$ & $-230 \pm 20$ & $2720 \pm 80$ & $+70 \pm 10$ & $-60 \pm 10$ \\
\hline $\mathrm{HR}(\mathrm{bt} / \mathrm{min})$ & $74.5 \pm 7.5$ & $76.7 \pm 8.5$ & $+2.2 \pm 1.0$ & $75.5 \pm 6.8$ & $-1.2 \pm 1.7$ & $+1.0 \pm 0.7$ \\
\hline Systolic SBP(mmHg) & $115.5 \pm 8.5$ & $118.5 \pm 10.5$ & $+3.0 \pm 2.0$ & $117.0 \pm 9.0$ & $-1.5 \pm 0.5$ & $+1.5 \pm 0.5$ \\
\hline Diastolic DBP $(\mathrm{mmHg})$ & $75.5 \pm 5.5$ & $79.0 \pm 7.0$ & $+3.5 \pm 1.5$ & $76.5 \pm 7.5$ & $-2.5 \pm 0.5$ & $+1.0 \pm 2.0$ \\
\hline Robinson's Index (IR) & $86.1 \pm 4.5$ & $90.9 \pm 7.0$ & $+4.8 \pm 2.5$ & $88.3 \pm 6.5$ & $-2.6 \pm 0.5$ & $+2.2 \pm 2.0$ \\
\hline $\begin{array}{l}\text { Ruffier-Dickson's Index } \\
\text { (RDI) }\end{array}$ & $9.2 \pm 3.4$ & $11.5 \pm 3.8$ & $+2.3 \pm 0.4$ & $10.6 \pm 3.6$ & $-0.9 \pm 0.5$ & $+1.4 \pm 0.2$ \\
\hline BMI $\left(\mathrm{kg} / \mathrm{m}^{2}\right)$ & $21.34 \pm 3.3$ & $22.23 \pm 3.2$ & $+0.89 \pm 0,1$ & $21.93 \pm 2.9$ & $-0.3 \pm 0.3$ & $+0.59 \pm 0.4$ \\
\hline Life index $(\mathrm{ml} / \mathrm{kg})$ & $48.4 \pm 3.7$ & $44.3 \pm 5.4$ & $-4.1 \pm 1.7$ & $46.1 \pm 5.2$ & $+1.8 \pm 0.2$ & $-2.3 \pm 1.5$ \\
\hline $\begin{array}{c}\text { Recovery time after } 20 \\
\text { squats }(\mathrm{sec})\end{array}$ & $92.5 \pm 10.5$ & $104.0 \pm 12.0$ & $+11.5 \pm 1.5$ & $98.0 \pm 11.0$ & $-6.0 \pm 1.0$ & $+5.5 \pm 0.5$ \\
\hline \multicolumn{7}{|c|}{ Group of boys $(n=32)$} \\
\hline Height $(\mathrm{cm})$ & $174.2 \pm 10.5$ & $175.4 \pm 9.7$ & $+1.2 \pm 0.8$ & $176.3 \pm 8.6$ & $+0.9 \pm 1.1$ & $+2.1 \pm 1.9$ \\
\hline Weight (kg) & $66.8 \pm 6.2$ & $69.3 \pm 8.0$ & $+2.5 \pm 1.8$ & $68.7 \pm 6.7$ & $-0.6 \pm 1.3$ & $+1.9 \pm 0.5$ \\
\hline $\mathrm{BK}(\mathrm{ml})$ & $3270 \pm 80$ & $3100 \pm 100$ & $-170 \pm 20$ & $3230 \pm 90$ & $+130 \pm 10$ & $-50 \pm 10$ \\
\hline $\mathrm{HR}(\mathrm{bt} / \mathrm{min})$ & $72.4 \pm 6.7$ & $74.2 \pm 7.5$ & $+1.8 \pm 0.7$ & $73.0 \pm 6.2$ & $-0.7 \pm 0.3$ & $+1.1 \pm 0.5$ \\
\hline Systolic SBP(mmHg) & $117.5 \pm 7.0$ & $118.0 \pm 8.5$ & $+1.5 \pm 1.5$ & $117.0 \pm 9.0$ & $-1.0 \pm 0.5$ & $-0.5 \pm 2.0$ \\
\hline Diastolic DBP (mmHg) & $77.5 \pm 6.5$ & $78.5 \pm 7.0$ & $+1.0 \pm 0.5$ & $77.0 \pm 7.5$ & $-1.5 \pm 0.5$ & $-0.5 \pm 1.0$ \\
\hline Robinson's Index (IR) & $85.1 \pm 3.7$ & $87.5 \pm 5.0$ & $+2.4 \pm 2.5$ & $85.4 \pm 4.5$ & $-2.1 \pm 0.5$ & $+0.3 \pm 0.7$ \\
\hline $\begin{array}{l}\text { Ruffier-Dickson's Index } \\
\text { (RDI) }\end{array}$ & $8.9 \pm 2.3$ & $9.6 \pm 2.9$ & $+0.7 \pm 0.6$ & $9.1 \pm 3.1$ & $-0.5 \pm 0.2$ & $+0.2 \pm 0.8$ \\
\hline BMI $\left(\mathrm{kg} / \mathrm{m}^{2}\right)$ & $22,05 \pm 3.6$ & $22.52 \pm 3.7$ & $+0.47 \pm 0,1$ & $22.09 \pm 3.2$ & $-0.43 \pm 0.1$ & $+0.04 \pm 0.4$ \\
\hline Life index $(\mathrm{ml} / \mathrm{kg})$ & $49.0 \pm 3.5$ & $44.7 \pm 4.8$ & $-4,3 \pm 0,8$ & $47.0 \pm 4.2$ & $+2.3 \pm 0.6$ & $-2.0 \pm 0.7$ \\
\hline $\begin{array}{c}\text { Recovery time after } 20 \\
\text { squats }(\mathrm{sec})\end{array}$ & $82.0 \pm 8.5$ & $91.0 \pm 11.0$ & $+9.0 \pm 2.5$ & $85.5 \pm 9.5$ & $-5.5 \pm 1.5$ & $+3.5 \pm 1.0$ \\
\hline
\end{tabular}


Analysis of the Index of Robinson (IR) showed that the quantitative assessment of the energy potential of girls at the beginning of the research was on the verge of good and satisfactory levels. Limitations of motor activity caused by COVID-19 led in the first phase of the research to worsening of the indicator (IR) to the satisfactory level, and in $11.2 \%$ of girls to the low level, indicating the appearance of signs of dysregulation of the cardiovascular system.

Analysis of the evaluation of the Ruffier-Dixon Index at different phases of the research showed that female students during the pandemic showed a significant decrease in physical performance of the heart. At the first phase there was the process of reducing the indicators from medium to satisfactory level, especially significant changes were observed in those female students who suffered with overweight. At the second phase of the research, the physical performance of the heart tended to improve, but their assessment remained at average level. During the year of observation, in the context of the COVID-19 pandemic, the indicators of the Ruffier-Dixon Index in girls did not reach the initial level, indicating deterioration in the physical performance of the heart.

Analysis of the morphofunctional abilities of the body in boys showed general tendency to deteriorate in IR, RDI, BMI, LI at the first phase of the research. It should be noted that they, in contrast to the indicators of girls, did not go beyond the unsatisfactory level of development. At the second phase of the research, the boys underwent processes of gradual restoration of morphofunctional parameters, which in their level of development almost reached the initial level. This fact indicates that despite the limitations of motor activity in the conditions of COVID-19 pandemic, the boys in 4-6 months began the processes of adaptation to the new conditions.

At the next phase of the experiment, we studied the effect of motor limitations caused by COVID-19 on students' physical fitness which are the results of their motor activity. The results are presented in table 2 .

The test results show the decrease in the physical abilities of students during the COVID-19 pandemic. Comparison of the results showed that the most negative changes occurred at the first phase of the research (June 2020). At the second phase of the experiment, the students were able to partially restore their physical shape (December 2020). The results of the second phase of the experiment showed improvement in all proposed exercises. At the same time, the general results of the experiment showed that students could not reach the level of indicators of the initial phase of the research. That is, the level of motor activity of students in the conditions of COVID-19 was much lower than normal, which did not contribute to the growth of their physical abilities and the growth of sports results in the proposed tests.

Table 2. Dynamics of indicators of physical condition of students at different phases of the experiment

\begin{tabular}{|c|c|c|c|c|c|c|c|}
\hline № & Tests & $\begin{array}{c}\text { At the } \\
\text { beginning of } \\
\text { the experiment }\end{array}$ & $\begin{array}{c}\text { At the end of } \\
\text { phase } 1\end{array}$ & Changes & $\begin{array}{l}\text { At the end of } \\
\text { phase } 2\end{array}$ & Changes & $\begin{array}{l}\text { General } \\
\text { changes }\end{array}$ \\
\hline \multicolumn{8}{|c|}{ Group of girls $(n=89)$} \\
\hline 1. & $\begin{array}{c}\text { Bench push-ups } \\
\text { (times) }\end{array}$ & $11.2 \pm 7.3$ & $7.4 \pm 5.3$ & $-3.8 \pm 2.0$ & $9.1 \pm 6.7$ & $+1.7 \pm 1.4$ & $-2.1 \pm 0.7$ \\
\hline 2. & $\begin{array}{c}\text { Standing } \\
\text { long-jump }(\mathrm{cm})\end{array}$ & $162 \pm 17.5$ & $151 \pm 18.2$ & $-11.0 \pm 0.7$ & $157 \pm 16.4$ & $+6.0 \pm 1.8$ & $-5.0 \pm 0.7$ \\
\hline 3. & $\begin{array}{c}\text { Balance holding } \\
\text { (sec) }\end{array}$ & $48.3 \pm 6.3$ & $42.6 \pm 8.8$ & $-5.7 \pm 2.5$ & $45.6 \pm 7.4$ & $+3.0 \pm 1.4$ & $-2.7 \pm 1.1$ \\
\hline 4. & Burpie's test (sec) & $19.0 \pm 5.5$ & $16.2 \pm 7.3$ & $-2.8 \pm 1.8$ & $17.3 \pm 6.2$ & $+1.1 \pm 1.1$ & $-1.7 \pm 0.7$ \\
\hline 5. & $\begin{array}{c}\text { Shuttle run } 4 \times 9 \mathrm{~m} \\
(\mathrm{sec})\end{array}$ & $11.12 \pm 0.64$ & $11.64 \pm 0.78$ & $-0.52 \pm 0.14$ & $11.32 \pm 0.53$ & $+0.32 \pm 0.25$ & $-0.20 \pm 0.11$ \\
\hline \multicolumn{8}{|c|}{ Group of boys $(n=32)$} \\
\hline 1. & Pull-up & $11.4 \pm 4.2$ & $8.2 \pm 5.6$ & $-4.2 \pm 1.4$ & $10.1 \pm 4.8$ & $+1.9 \pm 0.8$ & $-1.3 \pm 0.1$ \\
\hline 2. & $\begin{array}{c}\text { Standing } \\
\text { long-jump }(\mathrm{cm})\end{array}$ & $212 \pm 19.0$ & $202 \pm 22.5$ & $-10.0 \pm 3.5$ & $208 \pm 18.4$ & $+6.0 \pm 4.1$ & $-4.0 \pm 0.6$ \\
\hline 3. & $\begin{array}{c}\text { Balance holding } \\
(\mathrm{sec})\end{array}$ & $54.2 \pm 12.2$ & $47.6 \pm 10.8$ & $-6.6 \pm 1.4$ & $52.8 \pm 9.3$ & $+5.2 \pm 1.5$ & $-1.4 \pm 2.9$ \\
\hline 4. & Burpie's test (sec) & $26.7 \pm 4.4$ & $23.2 \pm 5.3$ & $-3.5 \pm 0.9$ & $25.2 \pm 5.5$ & $+1.9 \pm 0.2$ & $-1.5 \pm 1.1$ \\
\hline 5. & $\begin{array}{c}\text { Shuttle run } 4 \times 9 \mathrm{~m} \\
(\mathrm{sec})\end{array}$ & $10.05 \pm 0.51$ & $10.45 \pm 0.58$ & $-0.40 \pm 0.07$ & $10.24 \pm 0.63$ & $+0.21 \pm 0.05$ & $-0.19 \pm 0.12$ \\
\hline
\end{tabular}


It should be noted that some students $(12 \%$ - girls and $21 \%$ - boys) were able to recover their physical fitness. These are mostly students who led an active lifestyle before the pandemic was declared. The very desire to be physically active and go in for sports in difficult situations of limited motor activity allowed them to regain their physical conditions. At the same time, none of them managed to improve their results when performing the control tests. This fact indicates that independent classes in the conditions of restrictions allow only to maintain physical shape and do not contribute to the further development of physical abilities of students.

Comparative analysis of the dynamics of physical fitness of girls and boys (Fig.1-2.) showed that boys' processes of adaptation to the new conditions of limited motor activity were faster, as evidenced by the results of the second phase of the research. At the second phase of the research, the indicators of physical development of the boys approached the indicators of the initial stage of the research. Girls also showed the tendency to improve the indicators of physical fitness, but the dynamics of their recovery was inferior to the dynamics of recovery of boys.

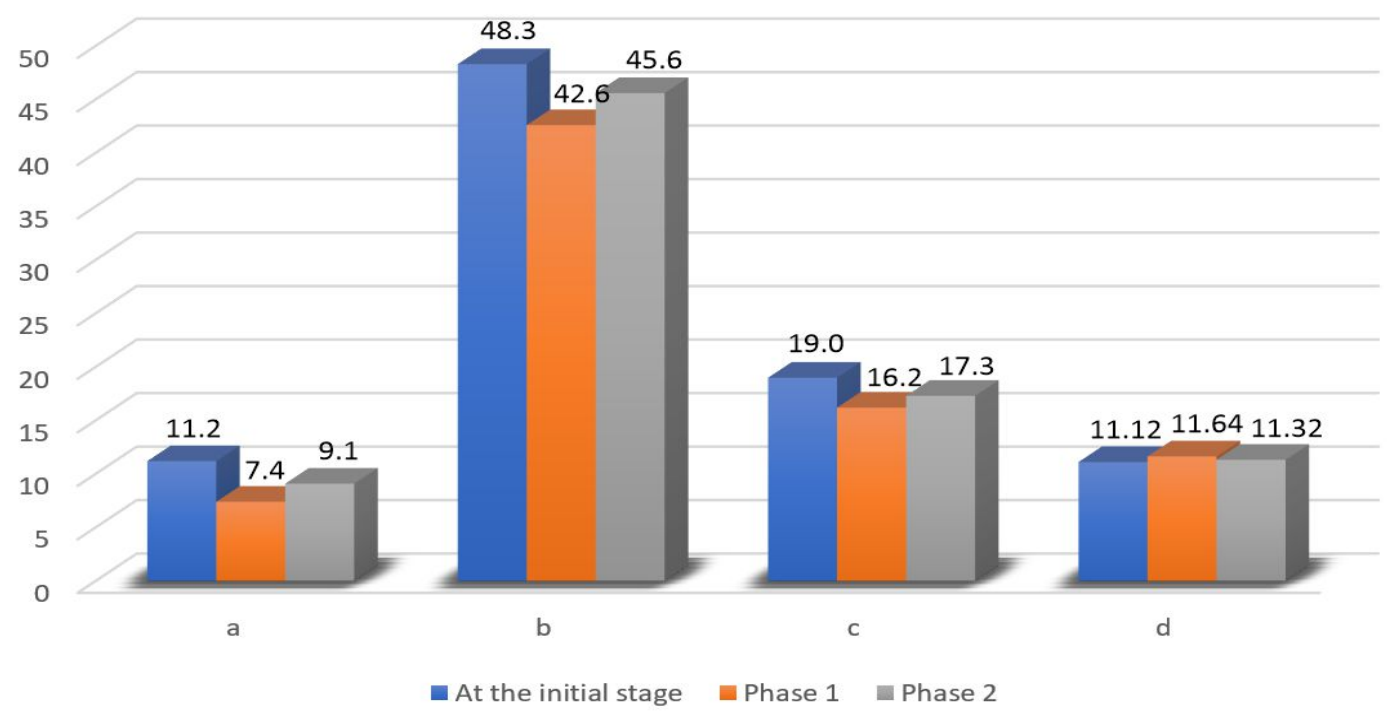

Where: $0-50$ indicators of physical development;

a) Development of strength;

b) Coordination abilities;

c) Development of speed and strength abilities;

d) Development of agility.

Figure 1. Dynamics of indicators of physical development of girls $(n=89)$

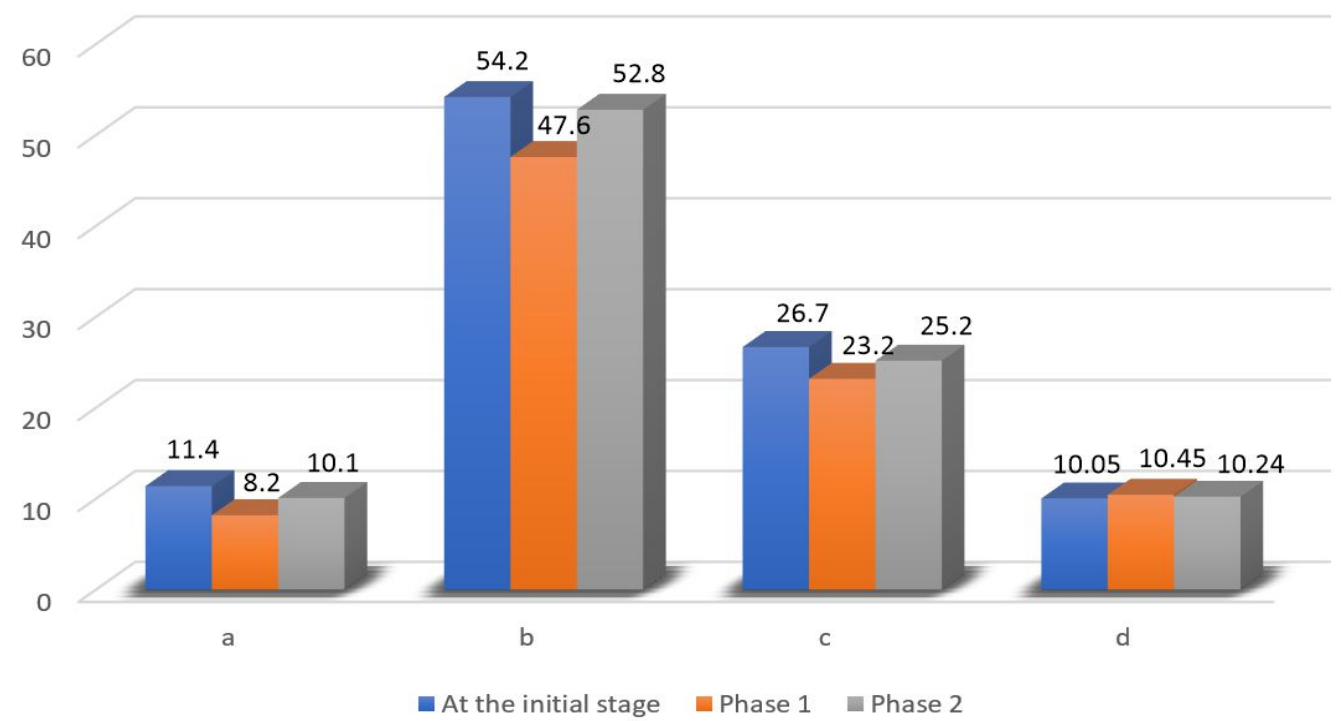


Where: $0-60$ indicators of physical development;
a) Development of strength;
b) Coordination abilities;
c) Development of speed and strength abilities;
d) Development of agility.

Figure 2. Dynamics of indicators of physical development of girls $(n=32)$

\section{Discussion}

Specially organized motor activity, as noted by Vasylenko N.I. 2014 [10] and Griban, G., Skoruy, O. et al. 2020) [11] is seen as a powerful means of strengthening the health of every person, it contributes to the quality of education and high efficiency of student youth. Deficiency of motor activity of student youth of Ukraine according to the research of Horelov, A.A., \& Rumba, O.H. 2013 [12]; Furtovy S.M. 2013 [13] is $60-75 \%$ of what is needed to maintain a normal level of health.

After conducting the research of physical activity and functional abilities of students in the conditions of COVID-19 restrictions, we obtained new data on indicators of physical development, functional status and morphofunctional abilities of students aged 17-19. The conducted comparative analysis with the initial indicators allowed us to examine the changes that took place in the bodies of students during the nine months in the conditions of quarantine restrictions on physical activity.

The results of our research confirm the results of studies by Hambali, S., Akbaruddin, A., Bustomi, D. et al. 2020 [7]; Nurulfa, R., Motto, C., Dlis, F. et al. 2020 [21] on changes occurring in the human body in the conditions of limited motor activity during the pandemic COVID-19. Our research supplemented and expanded the data of Mozolev, O., Polishchuk O., Kravchuk, L. et al. 2020 [6]; Hambali, S., Akbaruddin, A., Bustomi, D. et al. 2020 [7]; on the dynamics of morphofunctional and physical changes in accordance with the gender characteristics that occurred in students during the COVID-19 pandemic.

The conducted research expanded the scientific views of Anikeev, D.M. 2012 [17]; Horelov, A.A., \& Rumba, O.H. 2013 [12]; Vasylenko N.I. 2014 [10]; Griban, G., Skoruy, O. et al. 2020 [11] on the necessity of systematic assessment of the level of functional state, physical fitness and motor activity of students at each stage of training, which will allow to respond in a timely manner to their changes and adjust physical education programs for student youth.

Our research is based on the scientific views of modern specialists in the sphere of physical culture and sports. The researchers considered the problem of improving physical activity and improving the functional capabilities of students in conditions of various limitations while studying in higher education institutions in multiple investigations:

- Blavt O.Z. 2012; Blagiy O. L., Yachnyuk M. Yu. 2015; Leuciuc, F. 2019 [14-16] study the indicators of the level of physical fitness depending on the level of motor activity of students at different stages of training;

Anikeev, D.M. 2012; Voronetskiy, V.B. 2015 [17-18] deal with the analysis of external and internal factors in fluencing the dynamics of development of morphofunctional indicators of physical development of students;

- Zhamardiy, V., Shkola, O., Okhrimenko, I. et al. 2020; Mozolev, O., Bloshchynskyi, I., Alieksieiev, O. et al. 2019 [19-20] study the impact of modern fitness technologies on the indices of health and motor activity of students;

- Hambali, S., Akbaruddin, A., Bustomi, D. et al. 2020 [7]; Nurulfa, R., Motto, C., Dlis, F. et al. 2020 [21] implement the most effective and popular among young people modern kinds of sports, taking into account the limitations of COVID-19;

- Mozolev, O., Halus, O., Bloshchynskyi, I., \& Kovalchuk, R. 2019 [22] consider the training of specialists in the sphere of physical education and sports of the new generation, capable of timely changes in accordance with the new challenges of time and requirements of the society;

- Tsios A. 2014 [4]; Dorofieieva, O.E., Yarymbash, K.S. 2017; Zakharchenko, M. 2017 [23-24] study the problems of motivating student youth to maintain their health, the need for doing exercises and lead an active way of life.

\section{Conclusions}

1. Restrictions of motor activity lead to functional changes in the bodies of students, reducing their efficiency and recovery after physical exercises. In both groups, after four months of research, there was a deterioration in the performance of abilities of the respiratory system (LI); quantitative assessment of human energy potential (IR); physical performance of the heart (RDI); compliance of weight with the height (BMI); restorative functions of the body after physical exercises.

2. At the second phase of the research (after nine months) there was a gradual improvement of functional parameters in both groups, which indicates adaptation of students to the new conditions of limited motor activity. At the same time, the functional indicators failed to reach the initial level. 
3. The analysis of statistical data shows that during the first four months there was a decrease of indices of physical fitness of students, namely: the development of strength by $34 \%$ in girls $(p<0,001)$ and $28 \%$ in boys $(\mathrm{p}<0,001)$; coordination abilities by $12 \%$ in girls $(\mathrm{p}<0,01)$ and by $13 \%$ in boys $(\mathrm{p}<0,01)$; development of speed and strength abilities by $15 \%$ in girls $(p<0,01)$ and $13 \%$ in boys $(p<0,01)$; speed and strength development by $5 \%$ in girls $(p<0,05)$ and by $4 \%$ in boys $(\mathrm{p}<0,05)$.

4. Comparative analysis of the dynamics of physical fitness of girls and boys showed that boys' processes of adaptation and restoration of motor activity in the conditions of quarantine restrictions were faster. After nine months, in the majority of exercises tested, the boys' level of physical fitness reached $95-98 \%$ $(p<0,001)$ of the initial level; in girls $91-94 \%$ $(p<0,001)$. The performance of exercises for the development of strength in boys corresponded only to $88.6 \%$ of the initial level, and in girls $81.2 \%$.

5. Some students (12\% - girls and $21 \%$ - boys) were able to recover their physical fitness. These are mainly students who led an active lifestyle before the pandemic and sought additional physical exercises during quarantine restrictions. Independent trainings in conditions of restrictions allow only to maintain physical shape and only partially contribute to the further development of physical abilities of students.

6. We believe that in the period of quarantine restrictions, it is necessary to introduce into the educational process modern fitness technologies of general physical orientation with the use of Pilates, shaping and stretching as the main element of maintaining physical activity of students. Such classes can be conducted online 2-3 times a week for up to 1 hour. This approach will help to increase the level of motor activity, physical health and well-being of students and will maintain the level of development of physical qualities of girls and boys.

\section{Compliance with Ethical Standards}

\section{Conflict of Interest}

The authors declare that they have no conflict of interest.

\section{Ethical Approval}

All procedures performed in studies involving human participants were in accordance with the ethical standards of the institutional and/or national research committee and with the 1964 Helsinki declaration and its later amendments or comparable ethical standards.

\section{Informed Consent}

Informed Consent Informed consent was obtained from all individual participants included in the study. All subjects of the institutional survey gave consent for anonymised data to be used for publication purposes.

\section{REFERENCES}

[1] Turchyna, N. I. "Research on Students' Health and Level of Physical Development". Pedagogy, Psychology and Medical-Biological Problems of Physical Education and Sports, Vol. 12, pp. 150-152, 2010. (in Ukrainian)

[2] Mozolev, O., Kravchuk, L., Ostrovska, N., Nahorna, O., Polishchuk, O., \& Khmara, M. "Checking the effectiveness of the method of conducting physical education classes with 17-19 -year-old female students of special medical group". Journal of Physical Education and Sport, Vol. 20 (2), pp. 870 - 876, 2020. DOI:10.7752/jpes.2020.02124.

[3] Apanasenko, H. L. "Individual Health: Theory and Practice. Introduction to the Theory of Individual Health". Kiev-Medkniga. 2011. (in Ukrainian)

[4] Tsios A. "Motor Activity in Motivational and Value Orientations of Students". Physical education, sports and health culture in modern society. Lutsk: Lesia Ukrainka Eastern European National University, Vol.4 (28). pp. 83-87, 2014. (in Ukrainian)

[5] Kurok, O., Lucenko, G., Povstyn, O., Lutsenko, O. "Features of Distance Education in Ukraine during the Covid-19 Pandemic: Problems and Prospects" Universal Journal of Educational Research Vol. 8(11): pp. 5498 - 5504, 2020. DOI: $10.13189 /$ ujer.2020.081153.

[6] Mozolev, O., Polishchuk O., Kravchuk, L, Tatarin, O., Zharovska, O., Kazymir, V. "Results of monitoring the physical health of female students during the COVID-19 pandemic". Journal of Physical Education and Sport, Vol 20 Issue 6, pp. 3280 - 3287, 2020. DOI:10.7752/jpes.2020.s64 45.

[7] Hambali, S., Akbaruddin, A., Bustomi, D., Rifai, A., Iskandar, T., Ridlo, A., Meirizal, Y., Rusmana, R., Tyas, R. "The Effectiveness Learning of Physical Education on Pandemic COVID-19". Universal Journal of Educational Research Vol. 8(12 B), 8428 - 8432, 2020. DOI: 10.13189/ujer.2020.082649.

[8] Horelov, A. A., \& Rumba, O. H. "On the dependence of students' somatic health on the value of their motor activity". Bulletin of sports science, Vol. 2, 36-39, 2013. (in Ukrainian)

[9] Mozolev, O., Bloshchynskyi, I., Prontenko, K., Zdanevych, L., Kruty, K., Popovych, O., Pisotska, L. "Influence of fitness techniques integration on the development of physical qualities and morpho-functional state of adult females". Hum Mov. Vol. 22(1), pp. 55-63, 2021. doi: https://doi.org/10.5114/hm.2021.98465.

[10] Vasylenko, N. I. "Study of health indicators of university students in different times of the educational process". Physical culture, sport and health, Vol. 6, pp. 23-29, 2014. (in Ukrainian) 
[11] Griban, G., Skoruy, O., Pantielieiev, K., Brytan, Y., Tymchyk, M., Kharchenko, N., Skyrda, T., Halimov, A., Shorobura, I., Mozolev, O. "Influence of Physical Education Classes on the Level of Health and Fitness Competencies of Students". International Journal of Applied Exercise Physiology, Vol. 9 (12), pp. 107-118, 2020. Doi: 10.26655/IJAEP.2020.12.1

[12] Horelov, A.A., \& Rumba, O.H. "On the dependence of students' somatic health on the value of their motor activity". Bulletin of sports science, Vol. 2, pp. 36-39, 2013. (in Ukrainian)

[13] Furtovyi S.M. "The Problem of Lack of Physical Activity of Student Youth". Physical education of students. Vol..3, pp. 75-79, 2013. (in Ukrainian)

[14] Blavt O. Z. "Informative Indices of the Level of Physical Health and Physical Fitness of University Students". Pedagogy, Psychology and Medical-Biological Problems of Physical Education and Sports, Vol. 11, pp. 14-18, 2012. (in Ukrainian)

[15] Blagiy O. L., Yachnyuk M. Yu. "Analysis of indicators of physical condition of student youth". Bulletin of Chernihiv National Taras Shevchenko University. Physical education and sports, Vol. 12 (3), pp. 27-32, 2015. (in Ukrainian)

[16] Leuciuc, F. "Effect of a One-Semester Conditioning Activities on Physical Fitness of the Students". Revista Romaneasca pentru Educatie Multidimensionala, Vol. 11(4), pp. 136-146, 2019. doi:10.18662/rrem/162.

[17] Anikeev, D.M. "Motor activity in the student youth lifestyle". (Avtoref. dys. kand. nauk z fiz. vykhovannya i sportu), Nats. un-t fiz. vykhovannya i sportu Ukrayiny, Kyyiv, 2012. (in Ukrainian)

[18] Voronetskiy, VB." Motional activity as a part of the content of education in the institution of higher education". Journal of Education, Health and Sport, Vol. 5(7), pp. 620-630, 2015. doi: http://dx.doi.org/10.5281/zenodo.439431.
[19] Mozolev, O., Bloshchynskyi, I., Alieksieiev, O. Romanyshyna, L., Zdanevych, L., Melnychuk I., Prontenko K., \& Prontenko V. "Influence of modern fitness technologies on the state of health and development of motor abilities of 17-19-year-old female students". Journal of Physical Education and Sport, Vol. 19 (3), pp. 917 - 924, 2019. DOI: 10.7752 / jpes.2019.3132.

[20] Zhamardiy, V., Shkola, O., Okhrimenko, I., Strelchenko, O., Aloshyna, A., Opanasiuk, F., Griban, G., Yahodzinskyi, V., Mozolev, O., Prontenko, K. "Checking of the methodical system efficiency of fitness technologies application in students' physical education". Wiadomości Lekarskie, Vol. 73 (2), pp. 332-341, 2020. doi: 10.36740/WLek202002125.

[21] Nurulfa, R., Motto, C., Dlis, F. Tangkudung, J., Lubis, J., Junaidi. "Physical Education Survey during the COVID-19 Pandemic in Eastern Indonesia". Universal Journal of Educational Research, Vol. 8(12 B), pp. 8420 - 8427, 2020. DOI: $10.13189 /$ ujer.2020.082648.

[22] Mozolev, O., Halus, O., Bloshchynskyi, I., \& Kovalchuk, R. "Human resources management of educational development in sphere of physical culture and sports in Ukraine: comparative analysis (1992 - 2016)". Journal of Physical Education and Sport, Vol. 19(1), pp. 185-192, 2019. DOI:10.7752/jpes.2019.s1028.

[23] Dorofieieva, O.E., Yarymbash, K.S. "Influence of motivation for physical education on the level of physical health and physical preparedness of student youth". Scientific journal of the National Pedagogical University named after M.P. Drahomanov. Series 15: Scientific and Pedagogical Problems of Physical Culture, Vol. 3 (84), pp. 159-162, 2017. (in Ukrainian)

[24]Zakharchenko, M. "Formation of motivation for physical education of boys and girls". Physical Culture, Sport and Health of the Nation, Vol. 3 (22), pp. 82-87, 2017. (in Ukrainian) 